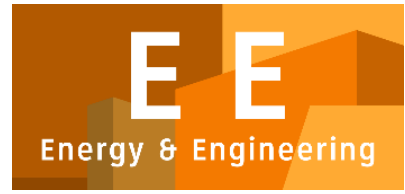

PAPER - OPEN ACCESS

\title{
Analisa Titik Operasi Optimum Pompa Slurry pada Bucket Wheel Dredger dengan Variasi Sudut Gali $30^{\circ}, 35^{\circ}$ dan $40^{\circ}$
}

\author{
Author \\ DOI \\ ISSN \\ : Robby Christian \\ E-ISSN \\ : 10.32734/ee.v1i1.108 \\ : 2654-7031 \\ : 2654-704X \\ Volume 1 Issue 1 - 2018 TALENTA Conference Series: Energy and Engineering
}

\section{(a) $(\mathbb{\theta})$}

This work is licensed under a Creative Commons Attribution-NoDerivatives 4.0 International License.

Published under licence by TALENTA Publisher, Universitas Sumatera Utara
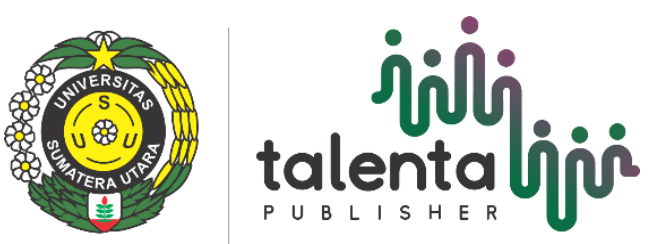


\title{
Analisa Titik Operasi Optimum Pompa Slurry pada Bucket Wheel Dredger dengan Variasi Sudut Gali $30^{\circ}, 35^{\circ}$ dan $40^{\circ}$
}

\author{
Robby Christian ${ }^{\mathrm{a}}$, Tekad Sitepu ${ }^{\mathrm{a}}$ \\ ${ }^{a}$ Fakultas Teknik, Universitas Sumatera Utara, Medan, 20155, Indonesia
}

Crobby25@yahoo.com

\begin{abstract}
Abstrak
PT.Timah (Persero) Tbk. merupakan perusahaan tambang timah dengan cadangan terbesar di dunia yang menggunakan kapal isap tipe Bucket Wheel Dredger sebagai salah satu metode penambangan lepas pantai. Untuk mendistribuskan material tambang dari dasar laut menuju unit penyaringan, digunakan air sebagai media pembawa dibantu dengan pompa melalui jaringan pemipaan. Pada proses pengerukan, ternyata didapat masih ada material logam timah yang tertinggal di dasar lautan. Hal ini menyebabkan pengerukan menjadi kurang maksimal. Oleh karena itu, diperlukan analisa untuk mencari kondisi operasi optimum untuk setiap kedalaman penggalian. Dalam penelitian ini, dilakukan perhitungan head secara teoritis dimana prosedur dimulai dengan pengumpulan data pendukung, kemudian melakukan perhitungan untuk mendapatkan hasil. Dalam kondisi lapangan, didapat perubahan luas penampang pipa dikarenakan erosi. Untuk menghitung head, digunakan persamaan Bernoulli, untuk kerugian head major dan head minor digunakan persamaan Darcy-Weisbach dimana kapasitas aliran adalah tetap $7747.2 \mathrm{~m} 3 / \mathrm{h}$ dengan variasi sudut gali $30^{\circ}, 35^{\circ}$, dan $40^{\circ}$ pada luas penampang dengan pemakaian baru, 1 bulan, 2 bulan, dan 3 bulan. Didapat titik operasi optimum pompa slurry untuk setiap sudut secara berurutan adalah pada 517.08 rpm, $517.44 \mathrm{rpm}, 520.96 \mathrm{rpm}$ untuk pemakaian baru; $517.44 \mathrm{rpm}, 517.44 \mathrm{rpm}, 521.664 \mathrm{rpm}$ untuk pemakaian satu bulan ; 517.44 rpm, $517.792 \mathrm{rpm}, 520.96 \mathrm{rpm}$ untuk pemakaian dua bulan; $511.808 \mathrm{rpm}, 512.16 \mathrm{rpm}, 513.92 \mathrm{rpm}$ untuk tiga bulan .
\end{abstract}

Kata kunci: Aliran Multifasa; Dredging; Kerugian Head; Pemipaan; Slurry;

\section{Pendahuluan}

Tingginya ketergantungan masyarakat akan logam timah yang diakibatkan oleh perkembangan teknologi serta bertambahnya jumlah penduduk dunia, membuat nilai serta semakin menipisnya cadangan logam di daratan mengharuskan para perusahaan penambang untuk memperluas areal penambangan nya hingga ke laut dengan cara proses pengerukan. Pengerukan dilakukan dengan menggunakan kapal keruk atau yang sering disebut dredger.

Di Indonesia, penambangan timah dilakukan oleh beberapa perusahaan, salah satunya yaitu PT Timah (Persero) Tbk yang dilakukan di Kepulauan Bangka dan Kepulauan Riau. Praktik penambangan oleh PT Timah dilaksanakan di darat dan di laut. Pada penambangan di laut, PT Timah memiliki beberapa kapal produksi timah, salah satunya Bucket Wheel Dredger $(B W D)$. Penambangan menggunakan $B W D$ membutuhkan biaya operasi yang tinggi, ditambah semakin menipisnya cadangan logam timah, para engineer diharuskan untuk menciptakan proses yang lebih efisien dan optimal. 
Pada penelitian ini pun, analisa dibatasi hanya pada keadaan kemiringan ladder $30^{\circ}, 35^{\circ}$, dan $40^{\circ}$, setiap sudut adalah berdasarkan keadaan pemakaian baru, bulan pertama, bulan kedua da bulan ketiga. Adapun tujuan daripada penelitian ini adalah untuk mencari kondisi operasi optimum yang seharusnya dilakukan saat proses penambangan timah menggunakan Bucket Wheel Dredger untuk kedalaman tertentu.

\section{Metode Penelitian}

Metode penelitian yang digunakan adalah metode analitik. Penelitian dimulai dengan proses pengumpulan data yang dibutuhkan. Pengumpulan data dilakukan di Kapal BWD milik PT Timah (Persero) Tbk yang berletk di perairan Penganak, Provinsi Bangka Belitung. Pengumpulan data dilaksanakan dengan metode observasi, riset pustaka, dan wawancara user.

\subsection{Pembagian Section}

Untuk memudahkan perhitungan, sistem pemipaan pada BWD dibagi atas 9 bagian yang mempunyai karakteristik yang berbeda.

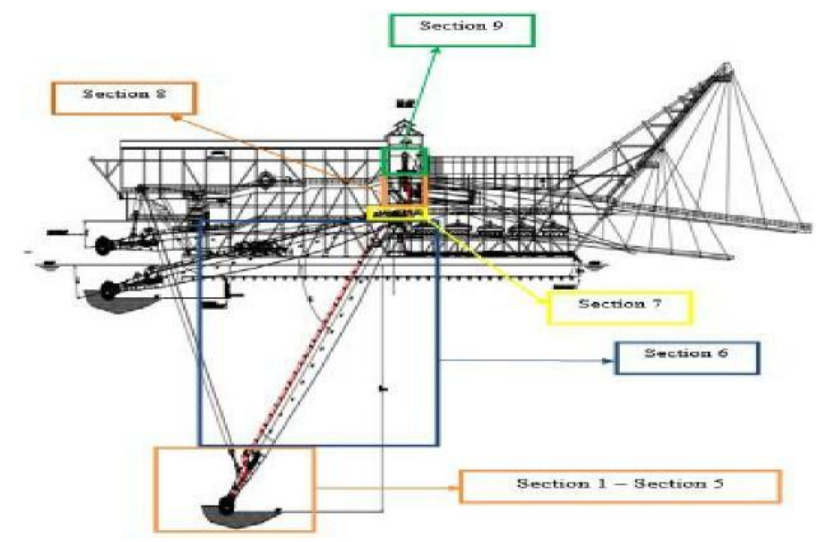

Gambar. 1. Pembagian Section

Tabel. 1. Spesifikasi Pipa Tiap Section

\begin{tabular}{cccccccccc}
\hline Section & 1 & 2 & 3 & 4 & 5 & 6 & 7 & 8 & 9 \\
\hline $\begin{array}{c}\text { Bahan } \\
\begin{array}{c}\text { Panjang } \\
(\mathrm{mm})\end{array}\end{array}$ & S235JR & S235JR & S235JR & Rubber & S235JR & $\begin{array}{c}\text { S235JR; } \\
\text { Rubber }\end{array}$ & Rubber & S235JR & S235JR \\
$\begin{array}{c}(\mathrm{mm}) \\
0\end{array}$ & 6880 & 300 & 2284 & 728 & 5604.5 & 69007 & 2000 & 11078 & 4800 \\
$(\mathrm{~mm})$ & 690 & 665 & 640 & 590 & 640 & 640 & 640 & 640 & 767 \\
\hline
\end{tabular}




\subsection{Kedalaman Gali Setiap Sudut}

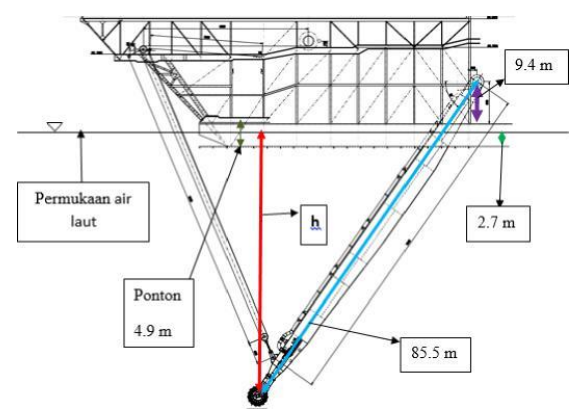

Gambar. 2. Skema kedalaman gali pada sudut $40^{\circ}$

Berdasarkan Gambar 2 diketahui bahwa panjang keseluruhan ladder adalah $85.5 \mathrm{~m}$, jarak antara permukaan air laut ke dasar ponton adalah $2.7 \mathrm{~m}$, tebal ponton adalah $4.9 \mathrm{~m}$, jarak pusat rotasi ladder ke ponton adalah $9.4 \mathrm{~m}$ dengan sudut pengoperasian $(\theta)$ sebesar $55^{\circ}$. Dengan demikian kedalaman penggalian $(\mathrm{h})$ dapat dihitung.

\subsection{Pengikisan Pipa}

Slurry yang abrasif menyebabkan terjadinya pengikisan pada pipa sehingga bentuk penampang pipa tidak lagi bulat . Jika pengikisan sudah mencapai 66\% dari ketebalan pipa, maka pipa akan diputar sebesar $120^{\circ}$ untuk memindahkan daerah dinding pipa yang menipis. Berdasarkan data yang diambil di lapangan, pipa mengalami pengurangan ketebalan sebesar $4.4 \mathrm{~mm}$ setelah sebulan pemakaian atau sebesar $22 \%$ dari ketebalannya, Laju pengikisan ini konstan setiap bulannya, sehingga pipa akan diputar setelah tiga bulan pemakaian.

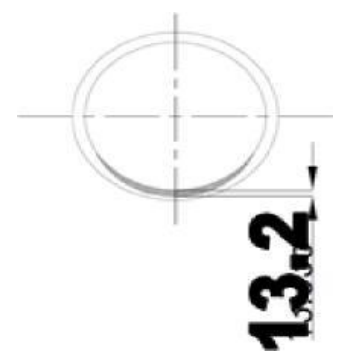

Gambar. 3. Ilustrasi Pengikisan Pipa

\subsection{Head Minor}

Head minor merupakan kerugian yang terjadi akibat komponen-komponen pada pipa seperti katup, belokan pada pipa, pembesaran dan pengecilan pipa secara tiba-tiba dan berbentuk kerucut, percabangan pipa, nosel, serta jalur masuk dan keluar pipa. Head minor dapat dihitung dengan persamaan (1).

$$
h_{L}=K \frac{V^{2}}{2 g}
$$

Dimana :

$h_{L}=$ Head minor $(\mathrm{m})$

$\Delta p=$ Perubahan tekanan $(\mathrm{Pa})$

$K=$ Koefisien kerugian head minor 


\subsection{Head Major}

Head major merupakan kerugian yang terjadi akibat adanya gesekan antara fluida dengan permukaan dinding pipa. Head major dapat dihitung dengan menggunakan persamaan Darcy Weisbach pada persamaan (2).

$$
h_{f}=f \frac{L}{D_{h}} \frac{V^{2}}{2 g}
$$

Dimana:

$f=$ Koefisien gesekan

$\mathrm{L}=$ Panjang pipa (m)

$D_{h}=$ Diameter hidraulik pipa $(\mathrm{m})$

$\mathrm{V}=$ Kecepatan rata-rata aliran fluida $(\mathrm{m} / \mathrm{s})$

$g=$ Percepatan gravitasi $=9,81 \mathrm{~m} / \mathrm{s}^{2}$

\subsection{Head Ratio}

Untuk menghitung head pada fluida Non-Newtonian, diperlukan metode khusus, salah satunya yaitu dengan menggunakan Head Ratio [7]. Head Ratio (HR) dan Efficiency Ratio (ER) adalah konstanta yang digunakan untuk menentukan head aktual serta efisiensi aktual yang terjadi pada suatu sistem pemipaan dengan fluida kerja slurry. Head aktual dapat dihitung dengan persamaan (3).

$$
h_{m}=\frac{h}{H R}
$$

Dimana:

$h_{m}=$ Total Head untuk fluida slurry (m)

$h=$ Total Head untuk fluida air (m)

$H R=$ Head Ratio

\section{Hasil dan Diskusi}

Dilakukan perhitungan nilai head pada sistem apabila tidak terdapat padatan pada fluida. Hasil perhitungan diperlihatkan pada Tabel 2.

Tabel. 2. Nilai head tanpa padatan

\begin{tabular}{ccccc}
\hline Lama Pemakaian (Bulan) & 0 & 1 & 2 & 3 \\
\hline Head & 39.0603 & 39.0937 & 38.9135 & 38.7355 \\
\hline
\end{tabular}

Pada Tabel 2 perhitungan dilakukan untuk variasi sudut ladder $30^{\circ}, 35^{\circ}$, dan $40^{\circ}$ dan didapat hasil yang sama. Hal ini dikarenakan air tidak perlu diberi usaha untuk mencapai permukaan air laut, jadi nilai $\mathrm{H}$ sebesar $39.0603 \mathrm{~m}$ adalah pembebanan dari titik permukaan air hingga titik keluar ditambah dengan head akibat perbedaan kecepatan, minor losses, dan major losses Tetapi nilai head berubah untuk bulan berikutnya akibat adanya perubahan luas penampang pipa.

Kemudian dilakukan perhitungan head jika pada fluida terdapat padatan. Besarnya head tergantung pada diameter impeler pompa slurry dan karakteristik padatan itu sendiri. Karakteristik padatan berupa Specific Gravity, Mean Diameter, dan Concentration by Volume. Dengan demikian dapat dihitung nilai head campuran seperti pada tabel 3. 
Tabel. 3. Nilai Head Slurry

\begin{tabular}{lccccc}
\hline \multirow{2}{*}{ Head Slurry (m) } & \multicolumn{5}{c}{ Lama Pemakaian (Bulan) } \\
\cline { 2 - 6 } & & 0 & 1 & 2 & 3 \\
\hline \multirow{3}{*}{ Sudut Penggalian } & $40^{\circ}$ & 43.3981 & 43.4333 & 43.2436 & 43.0562 \\
& $35^{\circ}$ & 43.0866 & 43.1218 & 42.9321 & 42.7447 \\
& $30^{\circ}$ & 42.7555 & 42.7907 & 42.6011 & 42.4137 \\
\hline
\end{tabular}

Pada tabel 3. didapat bahwa nilai beban terberat terdapat pada pemakaian baru pada sudut gali $40^{\circ}$, sedangkan pembebanan paling ringan terdapat pada bulan ketiga pada sudut gali $35^{\circ}$. Semakin lama waktu pemakaian, semakin besar pula luas penampang pipa, hal ini mengakibatkan kecepatan fluida yang mengalir pada dalam pipa menurun, sehingga nilai head yang terjadi juga ikut menurun. Untuk mendapatkan nilai operasi pompa optimal, nilai head slurry dicocokkan dengan menggunakan grafik kerja pompa, sehingga didapat nilai putaran optimal pompa sebagai berikut:

Tabel. 4. Nilai Putaran Optimal

\begin{tabular}{|c|c|c|c|c|c|}
\hline \multirow{2}{*}{$\begin{array}{c}\text { Putaran } \\
\text { (rpm) }\end{array}$} & & \multicolumn{4}{|c|}{ Lama Pemakaian (bulan) } \\
\cline { 2 - 6 } & & 0 & 1 & 2 & 3 \\
\hline \multirow{3}{*}{$\begin{array}{c}\text { Sudut } \\
\text { Penglihatan }\end{array}$} & $40^{\circ}$ & 520.960 & 521.664 & 520.960 & 513.920 \\
\cline { 2 - 6 } & $35^{\circ}$ & 517.440 & 517.440 & 517.792 & 512.160 \\
\cline { 2 - 6 } & $30^{\circ}$ & 517.080 & 517.440 & 517.440 & 511.808 \\
\hline
\end{tabular}

Berdasarkan Tabel 4, didapat nilai putaran optimal berkisar antara $511.808 \mathrm{Rpm}$ hingga $520.96 \mathrm{Rpm}$. Hasil ini lebih besar daripada putaran yang sering digunakan oleh operator yaitu sebesar 450 hingga 480 Rpm.

\section{Kesimpulan}

Titik operasi putaran pompa slurry dengan variasi sudut gali $30^{\circ}, 35^{\circ}$ dan $40^{\circ}$ pada luas penampang pemakaian baru, satu bulan, dua bulan dan tiga bulan secara berurutan adalah pada putaran $517.08 \mathrm{rpm}, 517.44 \mathrm{rpm}$, $520.96 \mathrm{rpm}$ untuk pemakaian baru; $517.44 \mathrm{rpm}, 517.44 \mathrm{rpm}, 521.664 \mathrm{rpm}$ untuk pemakaian satu bulan ; 517.44 rpm, $517.792 \mathrm{rpm}, 520.96 \mathrm{rpm}$ untuk pemakaian dua bulan; $511.808 \mathrm{rpm}, 512.16 \mathrm{rpm}, 513.92 \mathrm{rpm}$ untuk tiga bulan.

Total head yang timbul berdasarkan perhitungan apabila tidak ada padatan dalam aliran adalah sama pada setiap variasi sudut. Sedangkan total head tanpa padatan untuk pemakaian baru, satu bulan, dua bulan dan tiga bulan secara berurutan adalah sebesar $39.060 \mathrm{~m}, 39.093 \mathrm{~m}, 38.913 \mathrm{~m}$ dan $38.735 \mathrm{~m}$.

Total head yang timbul berdasarkan perhitungan bila padatan bercampur dalam aliran dengan variasi sudut gali $30^{\circ}, 35^{\circ}$ dan $40^{\circ}$ pada luas penampang pemakaian baru, satu bulan, dua bulan dan tiga bulan secara berurutan adalah $42.7555 \mathrm{~m}, 43.0866 \mathrm{~m}, 43.3981 \mathrm{~m}$ untuk pemakaian baru; $42.7907 \mathrm{~m}, 43.1218 \mathrm{~m}, 43.4333 \mathrm{~m}$ untuk pemakaian satu bulan; $42.6011 \mathrm{~m}, 42.9321 \mathrm{~m}, 43.2436 \mathrm{~m}$ untuk pemakaian dua bulan; $42.4137 \mathrm{~m}, 42.7447 \mathrm{~m}$, 43,0562 m untuk pemakaian tiga bulan. 


\section{Referensi}

[1] A Albar, R.E Randal, B Dwibarto, B.L Edge (2002) A bucket wheel dredge system for offshore tin mining beyond the $50 \mathrm{~m}$ water depth, Vol.29, Issue 14, p.1751-1767.

[2] Bruce R. Munson, Donald F. Young, Theodore H. Okiishi. 2002. Mekanika Fluida jilid I. PT. Erlangga. Jakarta.

[3] Daugherty, R. L.; J. B. Franzini; dan E. J. Finnemore, FluidMechanics and Engineering Applications, 9th ed., McGraw-Hill, New York, 1997.

[4] Lewis, J. M. and Randall, R. E.(2015) Prediction of Minor Loss Coefficient at Suction Inlet of Cutter Suction Dredge, Journal of Dredging, Western Dredging Association (WEDA), Vol. 15, No.1 p:14-42

[5] Mostafa H. Sharqawy, 2010 John H. Lienhard V dan Syed M. Zubair, Thermophysical Properties of Seawater: A Review of Existing Correlations and Data, Desalination and Water Treatment. Nayyar, Mohinder L, 2000, Piping Handbook, McGraw-Hill Inc., New York

[6] Vlasblom, W.J, 2003, Lecture Notes in Dredging Equipment and Technology, Delft University of Technology, Delft.

[7] Weir Slurry Group Inc, 2009, Slurry Pump Handbook Fifth Edition, New South Wales: Weir Slurry Group Inc. 